\title{
Withdrawn: 'Hepatoprotective effects of Tribulus terrestris L. (Zygophyllales: Zygophyllaceae) hydro-alcholic extract on non-alcoholic fatty liver-induced rats' [Braz. J. Biol. Sci. (2016), vol. 3, no. 5, p. 143-152]
}

\section{Fatemeh Almasi ${ }^{1}$, Mozafar Khazaei ${ }^{2 *}$, Shima Chehrei $^{3}$ and Ali Ghanbari $^{2 * * *}$}

1Student Research Committee, Kermanshah University of Medical Sciences, Kermanshah, Iran.

${ }^{2}$ Fertility and Infertility Research Center, Kermanshah University of Medical Sciences, Kermanshah, Iran.*Email: aghanbari@kums.ac.ir.

${ }^{3}$ Department of Biology, Arak Branch, Islamic Azad University, Arak, Iran. **Email: sh-chehreii@iau-arak.ac.ir.

This article has been withdrawn at the request of the authors. The Editor-in-Chief and Publisher apologizes for any inconvenience this may cause.

This is a notice of withdrawn of the article: "Hepatoprotective effects of Tribulus terrestris L. (Zygophyllales: Zygophyllaceae) hydro-alcholic extract on non-alcoholic fatty liver-induced rats" by Fatemeh Almasi, Mozafar Khazaei², Shima Chehrei and Ali Ghanbari published in the Braz. J. Biol. Sci. (2016), vol. 3, no. 5, p. 143-152, at the request of the correspondent author.

Due to accidentally submission and the author's later request (see above) the Editor-in-Chief of the Brazilian Journal of Biological Sciences decide to retract the paper.

The publisher apologizes for any inconvenience this may cause.

\section{“Dear editor}

Unfortunately, we regret continuing publication process of the paper because of our internal rules that allow us only to present our works in ISI listed journals. Seeing IF $=2.5$, this mistake was occurred by me and this condition is not related to nice Brazilian journal of biological sciences. Thus we could not fill the permission form. Please forgive us and withdraw the paper from further publication process.

Best wishes

Dr. Ali Ghanbari

Correspond author"

Received

July 19, 2016

Accepted

July 25, 2016

Released

December 31, 2016

Open Acess

Full Text Article

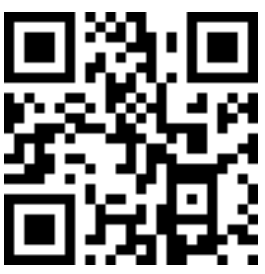

